\title{
Antibacterial Activity of Free Fatty Acids from Hydrolyzed Virgin Coconut Oil Using Lipase from Candida rugosa
}

\author{
Van Thi Ai Nguyen, ${ }^{1,2}$ Truong Dang Le, ${ }^{1}$ Hoa Ngoc Phan, ${ }^{2}$ and Lam Bich Tran ${ }^{2}$ \\ ${ }^{1}$ Institute of Biotechnology and Food Technology, Industrial University of Ho Chi Minh City, Ho Chi Minh City, Vietnam \\ ${ }^{2}$ Department of Food Technology, Faculty of Chemical Engineering, Ho Chi Minh City University of Technology, \\ Ho Chi Minh City, Vietnam
}

Correspondence should be addressed to Van Thi Ai Nguyen; nguyenthiaivan@iuh.edu.vn

Received 1 August 2017; Revised 20 September 2017; Accepted 2 October 2017; Published 13 November 2017

Academic Editor: Maurizio Averna

Copyright (c) 2017 Van Thi Ai Nguyen et al. This is an open access article distributed under the Creative Commons Attribution License, which permits unrestricted use, distribution, and reproduction in any medium, provided the original work is properly cited.

Free fatty acids (FFAs) were obtained from hydrolyzed virgin coconut oil (VCO) by Candida rugosa lipase (CRL). Four factors' influence on hydrolysis degree (HD) was examined. The best hydrolysis conditions in order to get the highest HD value were determined at VCO to buffer ratio 1:5 (w/w), CRL concentration $1.5 \%$ (w/w oil), $\mathrm{pH} 7$, and temperature $40^{\circ} \mathrm{C}$. After 16 hours' reaction, the HD value achieved 79.64\%. FFAs and residual hydrolyzed virgin coconut oil (HVCO) were isolated from the hydrolysis products. They were tested for their antibacterial activity against Gram-negative and Gram-positive bacteria, which can be found in contaminated food and cause food poisoning. FFAs showed their inhibition against Bacillus subtilis (ATCC 11774), Escherichia coli (ATCC 25922), Salmonella enteritidis (ATCC 13076), and Staphylococcus aureus (ATCC 25923) at minimum inhibitory concentration (MIC) of 50\%, 60\%, 20\%, and 40\%, respectively. However, VCO and HVCO did not show their antibacterial activity against these tested bacteria.

\section{Introduction}

VCO is extracted from fresh kernel by using either cold press or centrifuge process. It does not go through refined, bleached, and deodorized process (RBD). Therefore, its physical properties as flavor, color, and so forth are less changed than RBD oil. VCO has many advantages in skin care, promotes the growth of hair, and enhances the beauty. Antioxidant activity and phenolic compounds in VCO also was conducted by some studies; it was suggested that the consumption of food containing phenolic compound will have a positive contribution in health [1].

Aside from benefits above, VCO is also good in health promotion and prevents some diseases because of the presence of FFAs in VCO. FFAs in VCO are rich in medium chain fatty acids (MCFAs) in which lauric acid takes the highest percentage about $46-48 \%$. MCFAs in VCO are easily digested and absorbed, but fat is harder because it contains long chain fatty acids which need going through circulatory system before absorbing, so VCO can be used to replace cooking oil in daily meal to improve digestion. Moreover, MCFAs are also good for obese people because they increase energy expenditure more than usual. And MCFAs are directly absorbed from the intestine and burned in the liver; this makes them have a feeling which is always early satiety, and weight is decreased [2]. And also absorbing and burning directly in liver make MCFAs not take part in biosynthesis and transport of cholesterol. Thus, MCFAs in VCO have cardioprotective ability [3]. MCFAs also showed antifungal activity; Shino and coworkers (2016) exhibited a comparison of antimicrobial activity of chlorhexidine, coconut oil, probiotics, and ketoconazole on Candida albicans isolated in children with early childhood caries [4]. Parfene and coworkers (2013) gave a result about antifungal activity against Yarrowia lipolytica of MCFAs from crude coconut oil [5]. MCFAs have effective ability to inhibit some species of virus by breaking their membranes [3]. And antibacterial activity of MCFAs was also conducted by some previous studies; Kim and Rhee (2016) presented that MCFAs 
were antibacterial agents against Escherichia coli [6]. Shilling and coworkers (2013) also studied antimicrobial effect of VCO and MCFAs against Clostridium difficile [7].

MCFAs are antibacterial agents; this was demonstrated by previous studies, but MCFAs used in their studies were in form of pure chemical. Therefore, the aim of this study was to use FFAs extracted from hydrolyzed VCO and evaluate their antibacterial against Bacillus subtilis (ATCC 11774), Escherichia coli (ATCC 25922), Salmonella enteritidis (ATCC 13076), and Staphylococcus aureus (ATCC 25923), which can be found in food and cause food poisoning. At the same time, the resistance of VCO and HVCO against these tested bacteria was also evaluated.

\section{Materials and Methods}

2.1. Materials. VCO was sponsored by Luong Quoi Coconut Co., Ltd. (Ben Tre Province, Vietnam). Candida Rugosa lipase (CRL) (Type VII, $\geq 700$ unit/mg solid) was purchased from Sigma-Aldrich Co. (Canada). Chemicals used in this study were $\mathrm{KOH}$, n-hexane, and iso-octane and all other chemicals from Merck (Germany) and China were analyzed with purification more than $95 \%$. Mediums used in antibacterial test were Nutrient Broth (NB) (Italy), Mueller Hinton Agar (MHA) from HiMedia Laboratories Pvt. Ltd (India), and Mueller Hinton Broth (MHB) from Titan Biotech Ltd (India). And four types of bacteria used in this study were Bacillus subtilis (ATCC 11774), Escherichia coli (ATCC 25922), Salmonella enteritidis (ATCC 13076), and Staphylococcus aureus (ATCC 25923) provided by Microbiologics Co. (USA).

Devices used in this study were high speed homogenizer (IKA T25 digital ULTRA-TURRAX, Germany), overhead stirrer (OS20, USA), orbital shaker incubator (LM-2575RD) from Yihder Technology Co. (Taiwan), evaporator (IKA RV digital V) from Germany, and GC-FID SHIMADZU 2010 Plus (Japan).

2.2. Hydrolysis of VCO. VCO dissolved in iso-octane (VCO to solvent ratio $1: 1(\mathrm{w} / \mathrm{w})$ ) and phosphate buffer solution to adjust $\mathrm{pH}$ condition was placed in a $250 \mathrm{~mL}$ Erlenmeyer flask [8]. Emulsification of the mixture was carried out by using a stirrer at speed of $10000 \mathrm{rpm}$ in 15 minutes; then the appropriate amount of lipase was added and dissolved by stirring at speed of $350 \mathrm{rpm}$ in 5 minutes. The reaction was conducted in orbital shaker incubator at speed $150 \mathrm{rpm}$ for 2 hours. To stop the reaction, add $1 \mathrm{ml}$ ethanol $99.5 \%$ into the erlenmeyer flask.

The hydrolysis degree (HD) was calculated as the following formula [9]:

$$
\mathrm{HD}=\frac{V_{\mathrm{KOH}} * M_{\mathrm{KOH}} * M_{\mathrm{FFAs}}}{10 * m}(\%),
$$

where $V_{\mathrm{KOH}}$ is the volume of potassium hydroxide $(\mathrm{KOH})$ titrated $(\mathrm{mL}), M_{\mathrm{KOH}}$ is the molarity of $\mathrm{KOH}$ solution $(\mathrm{mol} / \mathrm{L})$, $M_{\text {FFAs }}$ is the average molecular weight of free fatty acids, and $m$ is mass of $\operatorname{VCO}(\mathrm{g})$.

2.3. Obtaining FFAs. The process was carried out according to the method of Shimada and coworkers (1998) [10]. The excess of $0.5 \mathrm{~N} \mathrm{KOH}$ was added to the hydrolyzed mixture to neutralize the released FFAs. Separatory funnel was used to extract FFAs and HVCO (tri-, di-, and monoglyceride). The upper phase containing HVCO dissolved in n-hexane was purified by using rotary evaporator. The lower phase containing FFAs was acidified with $4 \mathrm{~N} \mathrm{HCl}$ solution and then was extracted by n-hexane. FFAs and HVCO were analyzed composition by Gas Chromatography with Flame Ionization Detector (GC-FID).

2.4. Antibacterial Activity Test. The test was conducted following disk diffusion method. Firstly, bacterial inoculum suspension was diluted in saline and was adjusted to get the final inoculum to $1.5 \times 10^{6} \mathrm{CFU} / \mathrm{mL}$ [11]. Mix the volume of $1 \mathrm{~mL}$ bacterial inoculum to $15 \mathrm{~mL}$ of MHA and wait until the media solidified [12]. Paper discs with diameter of $6 \mathrm{~mm}$ containing different solutions such as gentamicin, VCO, HVCO, and FFAs were placed in agar surface and then were incubated for 24 hours at $37^{\circ} \mathrm{C}$. The antibacterial activity was determined by measuring the diameter of inhibition zone.

2.5. Determining the Minimum Inhibitory Concentration (MIC). MIC was conducted following the broth macrodilution method. Bacterial inoculum suspension was diluted directly in $\mathrm{MHB}$ and was adjusted to get final inoculum to $5 \times 10^{5} \mathrm{CFU} / \mathrm{mL}$. The antibacterial agent (FFAs) was prepared by diluting FFA directly in MHB to get dilution series $100 \%, 90 \%, \ldots, 10 \% .1 \mathrm{~mL}$ of bacterial inoculum was added to each tube containing $1 \mathrm{~mL}$ of dilution series of FFAs (positive control tube only has $\mathrm{MHB}$ ) and mixed the mixture. The tubes were incubated at $35^{\circ} \mathrm{C}$ from 16 to 20 hours before recording. The MIC is the lowest concentration of FFAs that completely inhibits growth of the bacteria in the tube. It was compared with positive control tube when determining growth end points. The results of this test are valid if growthcontrol well is definitely turbid or diameter of colonies $\leq$ $2 \mathrm{~mm}[13]$.

All the experiments were carried out in triplicate and the data collected were statistically analyzed by using R software.

\section{Results and Discussion}

3.1. Effect of VCO to Buffer Ratio. Lipase catalyzes hydrolysis reaction at interfacial area of emulsion. There are more bonds between water and oil when amount of buffer increases, so lipase has more substrates to be catalyzed leading to increase of hydrolysis degree. However, the excess of water amount will decrease hydrolysis degree because of substrate competition by binding to lipase [8]. In Figure 1(a) the VCO to buffer ratio of $1: 5(\mathrm{w} / \mathrm{w})$ showed the highest hydrolysis degree. Therefore, the next experiment will be carried out at this ratio.

3.2. Effect of CRL Concentration. CRL concentration has a significant effect on hydrolysis degree. Increasing lipase concentration will get a high hydrolysis degree, but when the interface of emulsion is saturated with lipase concentration, adding more lipase will not get a higher hydrolysis degree [14]. From Figure 1(b) the hydrolysis degree cannot increase at CRL concentration of $1.5 \%$ plus anymore. As a result, the 


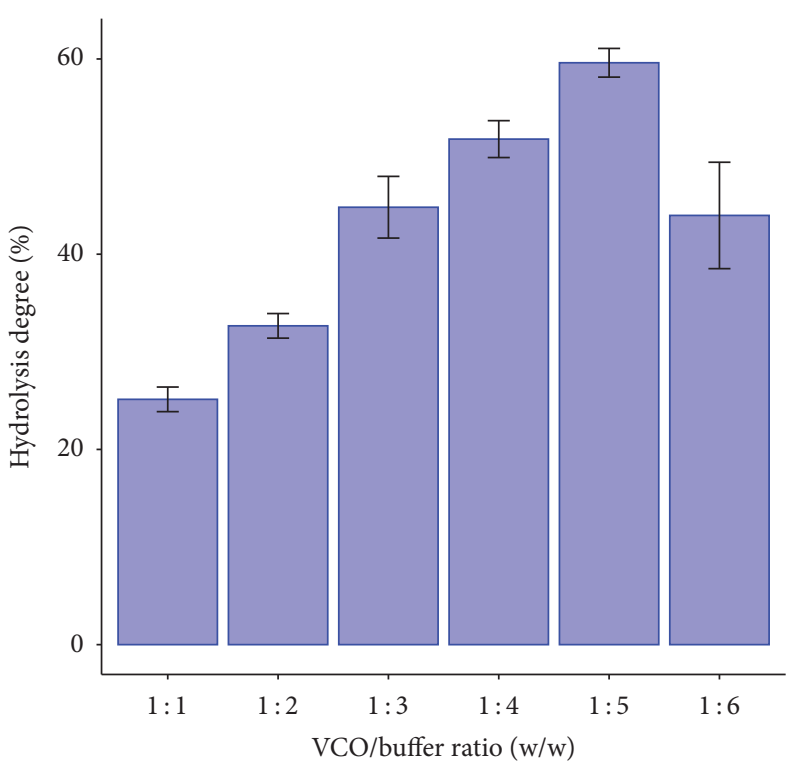

(a)

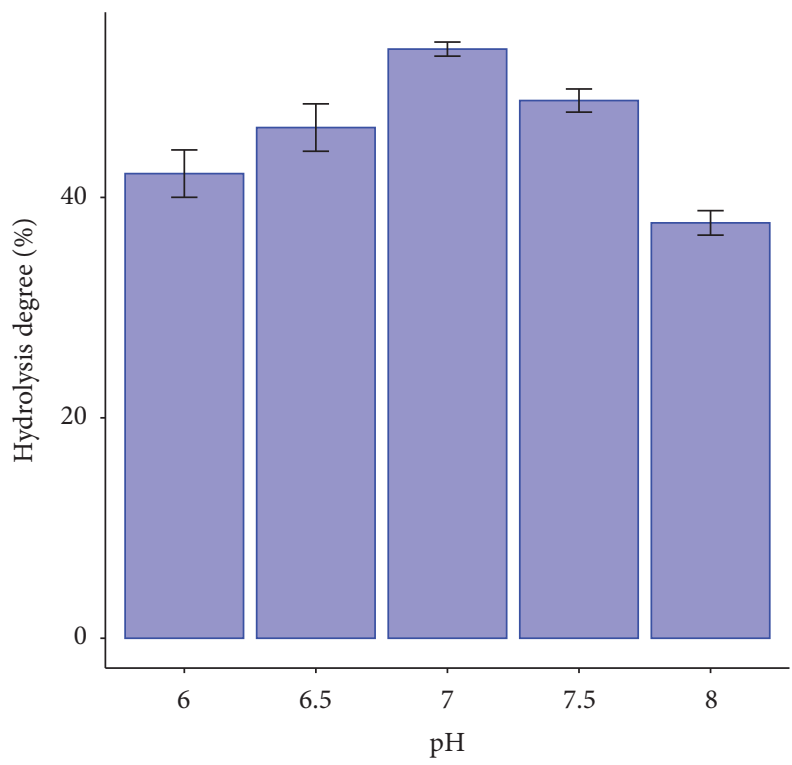

(c)

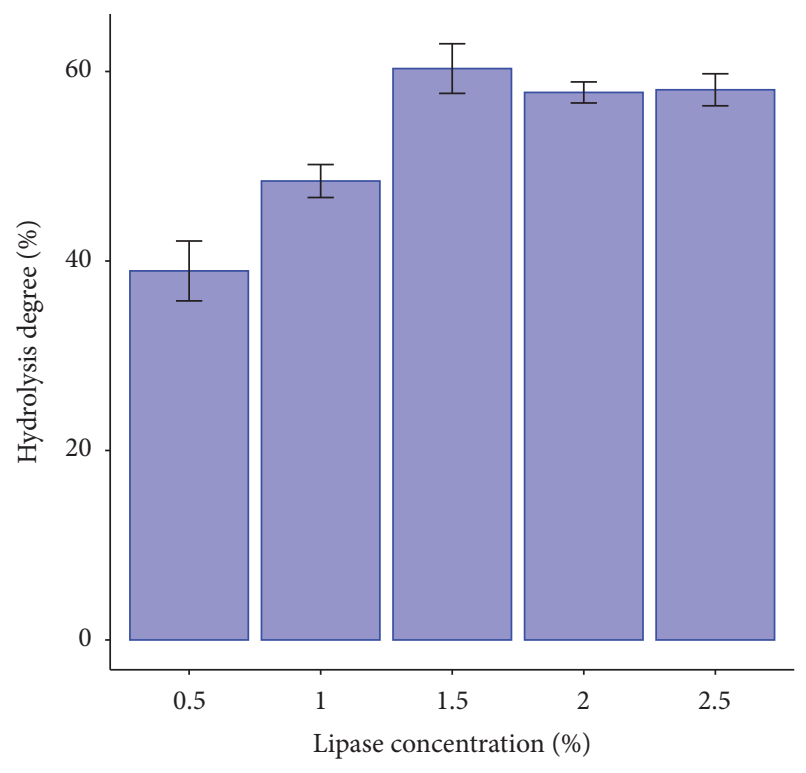

(b)

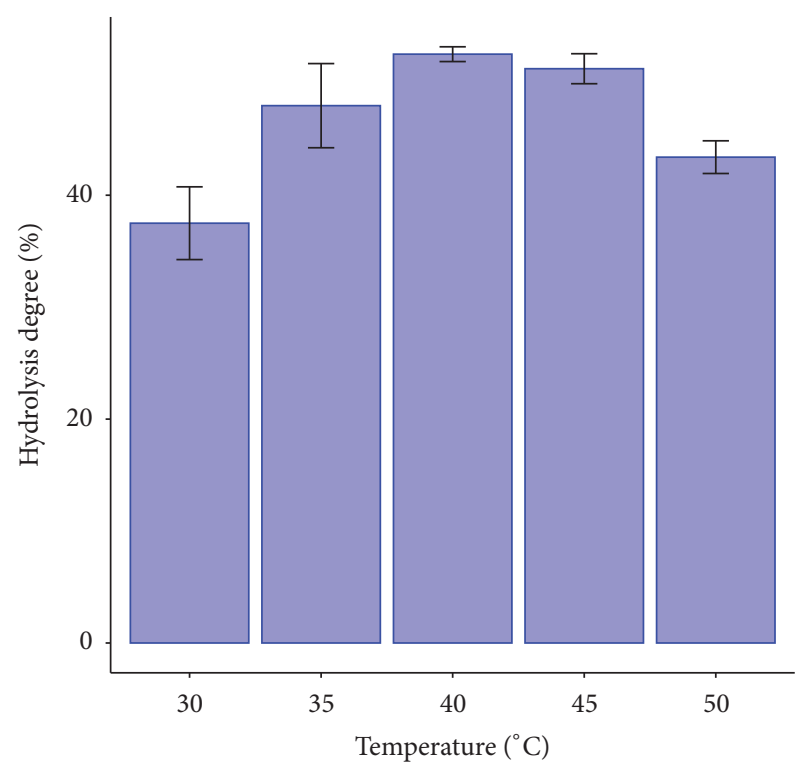

(d)

FIGURE 1: The rate of VCO to buffer (a), CRL concentration (b), pH (c), and temperature (d) effect on hydrolysis degree of VCO by CRL.

CRL concentration of $1.5 \%$ was chosen to carry out next experiments.

3.3. Effect of $p H$. Each lipase has an optimum $\mathrm{pH}$ condition. Changed $\mathrm{pH}$ range affects the ionization of substrate, free lipase, or lipase-substrate complex. Either high $\mathrm{pH}$ or low $\mathrm{pH}$ will make lipase denatured; substrate is broken down leading to a decrease of hydrolysis degree [15].

According to Figure 1(c), pH 7.0 was the best condition for hydrolysis reaction. And this result also was equivalent to some studies as Sharma and coworkers (2013) on hydrolysis of cod liver oil using CRL for fatty acid production. The process was carried out at $\mathrm{pH} 7.0$ [8]. Hydrolysis of soybean oil using CRL was also carried out at $\mathrm{pH} 7.0$ [16]. In the research of Freitas and coworkers (2007) on hydrolysis of soybean oil by using 3 types of lipase, among them was CRL with $\mathrm{pH}$ for hydrolysis reaction being 7.0 [17].

3.4. Effect of Temperature. Temperature has a strong effect to hydrolysis degree of lipase. When increase temperature, lipase becomes flexible; thus the hydrolysis degree is also increased. Moreover, increasing temperature will decrease viscosity of mixture reaction. This makes lipase easy to bond to a substrate; therefore the hydrolysis degree is increased. 


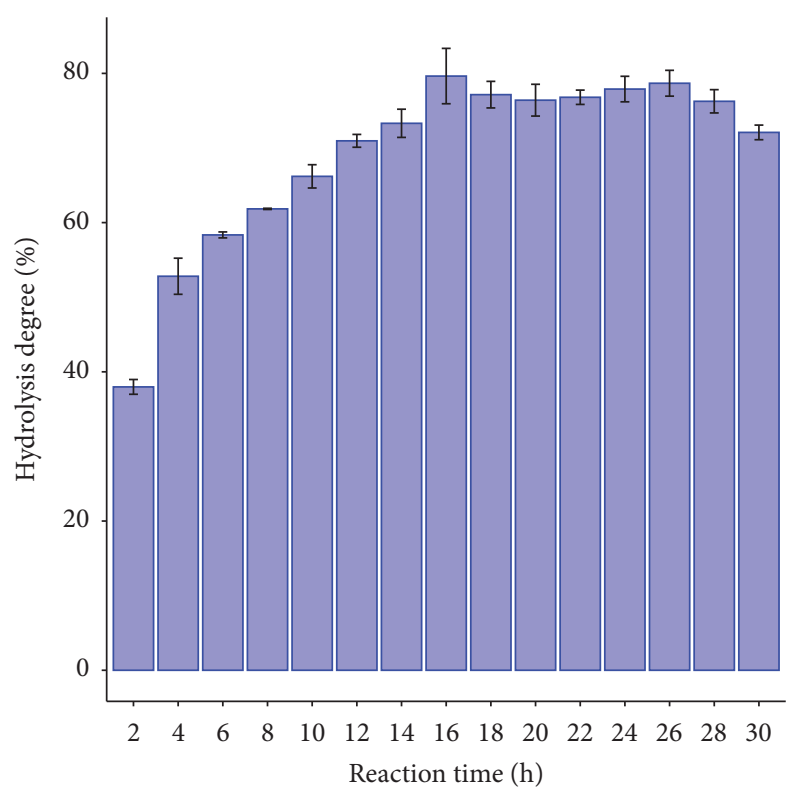

FIGURE 2: Time course of VCO hydrolysis catalyzed by CRL.

However, very high temperature will denature lipase because lipase's nature is protein; as a result, hydrolysis degree is decreased [15].

As shown in Figure 1(d), the highest hydrolysis degree was obtained at $40^{\circ} \mathrm{C}$. And this result was equivalent to some studies as hydrolysis of soybean oil by using CRL at $40^{\circ} \mathrm{C}$ of Freitas and coworkers (2007) [17]; Zhou and coworkers (2015) used CRL to hydrolyze Jatropha oil to produce biodiesel at $40^{\circ} \mathrm{C}$ [18]. Yiğitoğlu and Temoçin (2010) also conducted a research on hydrolysis of vegetables oil by using enzyme immobilized and free CRL at $40^{\circ} \mathrm{C}$ [19].

3.5. Hydrolysis Time. After 16 hours' reaction, the highest hydrolysis degree was achieved 79.64\% (Figure 2). When comparing the result with other previous studies, hydrolysis degree of, for example, soybean oil by CRL was $70 \%$ after 24 hours' reaction [17]. On the other hand, tuna fish oil was hydrolyzed by using CRL, after 24 hours' reaction; the hydrolysis degree achieved was $86.5 \%$ [20]. In this research, the hydrolysis time was shorter than other studies, but it got equivalent hydrolysis degree. Hence, it can be understood that using iso-octane in this hydrolysis reaction had a positive effect. The presence of iso-octane in reaction mixture decreased VCO viscosity. VCO was emulsified easily and increased the interface of VCO and water, so this made CRL have more opportunity to contact with substrate and easily catalyze hydrolysis reaction [21]. As such, it shortened time course of VCO hydrolysis reaction.

3.6. Antibacterial Test. According to Table 1 and Figure 3, FFAs showed clearly antibacterial activity on 4 types of bacteria. Diameter of inhibition zone of FFAs on each bacteria was different. FFAs' antibacterial activity on Salmonella enteritidis was stronger than Staphylococcus aureus and Escherichia coli, so the result demonstrated that FFAs extracted from
TABLE 1: Diameter of inhibition zone on 4 types of bacteria.

\begin{tabular}{lccc}
\hline \multirow{2}{*}{ Bacteria } & \multicolumn{3}{c}{ Diameter of inhibition zone \pm SD (mm) } \\
& FFAs & HVCO & VCO \\
\hline Bacillus subtilis & $11.33 \pm 1.15$ & 6 & 6 \\
Escherichia coli & $8.67 \pm 0.58$ & 6 & 6 \\
Salmonella enteritidis & $10.33 \pm 0.58$ & 6 & 6 \\
Staphylococcus aureus & $8.33 \pm 0.58$ & 6 & 6 \\
\hline
\end{tabular}

TABLE 2: Minimum inhibitory concentration of FFAs against four types of bacteria.

\begin{tabular}{lc}
\hline Bacteria & MIC (\%) \\
\hline Bacillus subtilis & 50 \\
Escherichia coli & 60 \\
Salmonella enteritidis & 20 \\
Staphylococcus aureus & 40 \\
\hline
\end{tabular}

hydrolyzed product were antibacterial agents. It was equivalent to some authors using FFAs in the form of pure chemicals. Shilling and coworkers (2013) showed the result of antibacterial ability of MCFAs (lauric acid in the form of pure chemicals) against Clostridium difficile. Moreover, hydrolyzed VCO also had an effect on the growth of Clostridium difficile because FFAs were released after hydrolysis of VCO [7]. Bergsson and coworkers (2002) studied antibacterial effect of fatty acids against Helicobacter pylori and the result exhibited that, among fatty acids, MCFAs were antibacterial agent [22]. The study of Kim and Rhee (2016) also showed that MCFAs could inhibit the growth of Escherichia coli [6].

VCO did not show its antibacterial activity against these tested bacteria. This was equivalent to the result of Shilling and coworkers (2013) in using VCO to inhibit Clostridium difficile, and VCO had a negative result [7].

HVCO in this study did not show its antibacterial ability although it might contain monoglyceride. This could be explained that, in this study, HVCO only contained a small amount of monoglyceride, so it did not have much enough to inhibit bacteria.

3.7. Minimum Inhibitory Concentration (MIC). The result of MIC was shown in Table 2 and Figures 4 and 5. The MIC of FFAs against Salmonella enteritidis was lowest while Escherichia coli needed concentration of FFAs up to $60 \%$ to inhibit it, so this showed that minimum concentration of FFAs to inhibit bacteria was completely different; it did not distinguish which is Gram-negative or Gram-positive bacteria.

\section{Conclusions}

This research found the best hydrolysis conditions of VCO under four parameters: VCO to buffer ratio, lipase concentration, $\mathrm{pH}$, and temperature. Using lipase to hydrolyze VCO received the less changed FFAs because the hydrolysis reaction is conducted under milder condition of $\mathrm{pH}$ and temperature than acidic or alkaline hydrolysis. And enzymatic 

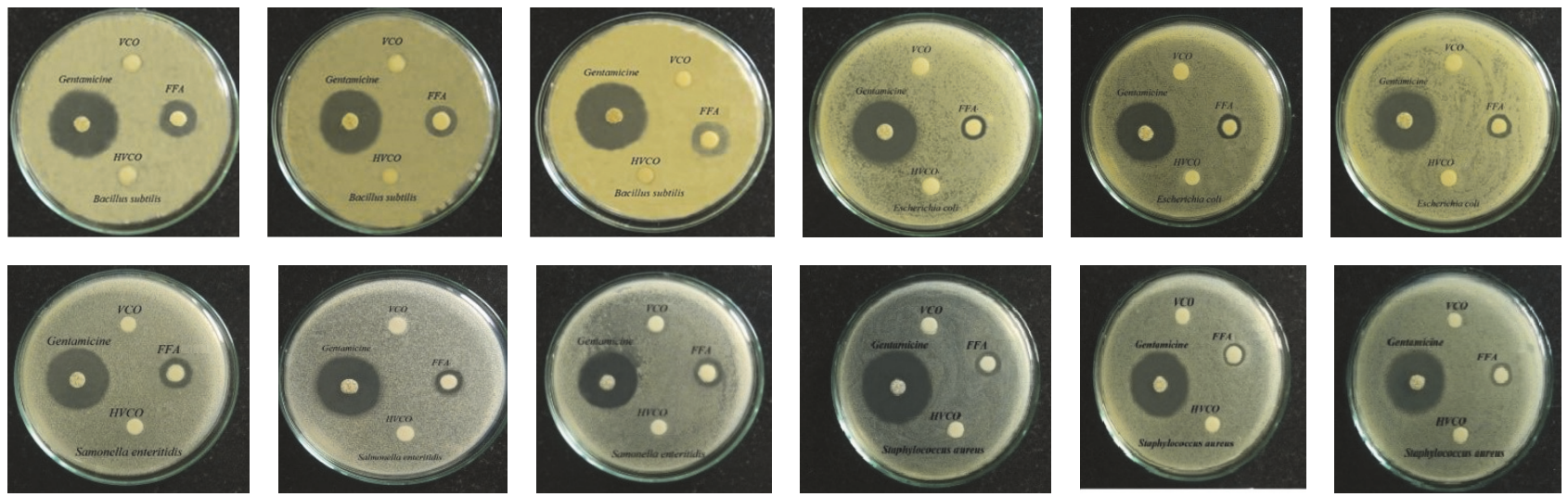

Figure 3: Antibacterial activity of VCO, HVCO, FFAs, and gentamicin against 4 types of tested bacteria.
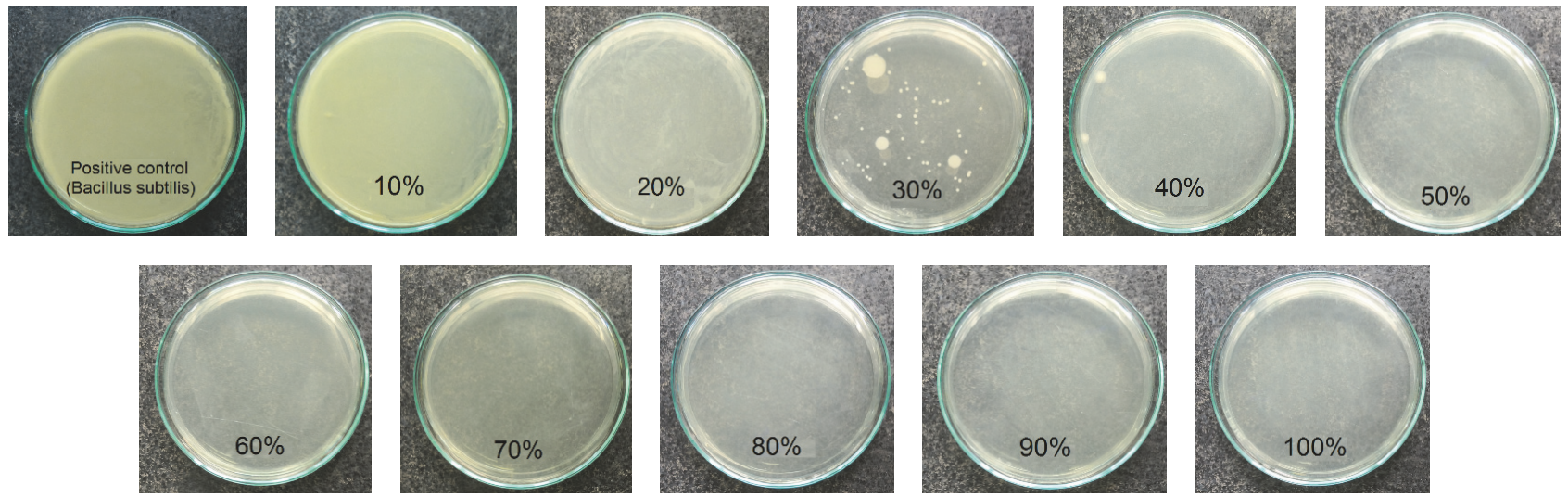

(a)
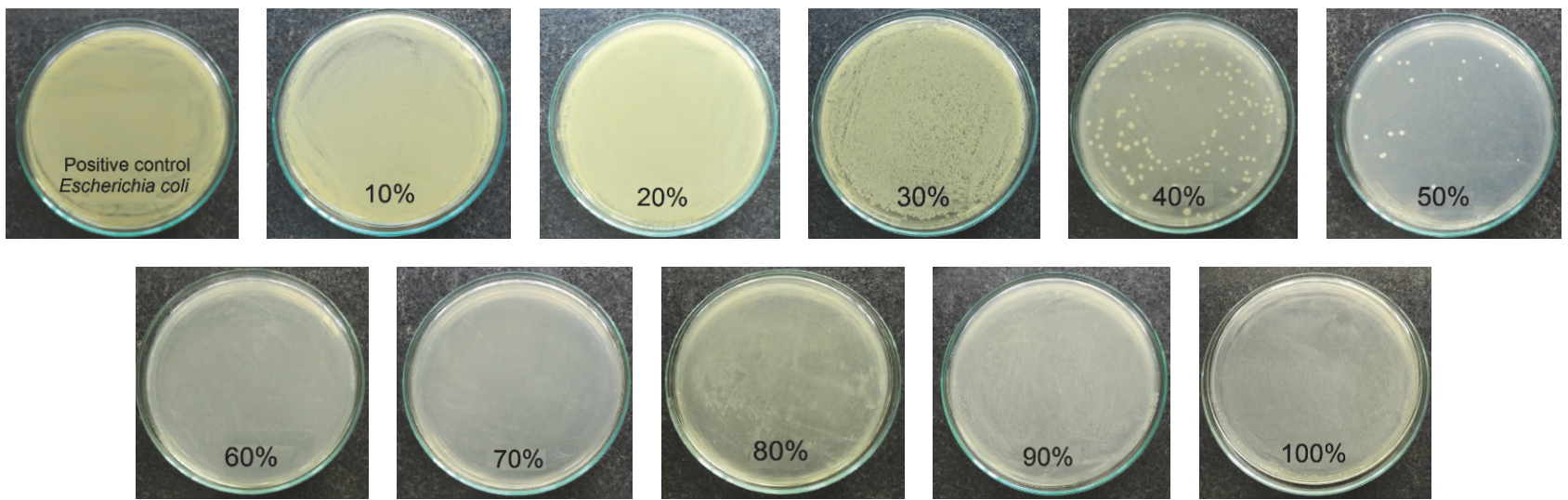

(b)

FIgURE 4: MIC of FFAs against Bacillus subtilis (a) and Escherichia coli (b).

hydrolysis can avoid some danger from undesirable sidereaction, not affecting color of products or limiting oxidized products so that FFAs can be applied in other fields as food preservation, pharmaceuticals, and so forth. Moreover, using iso-octane to dissolve VCO saved the time of hydrolysis reaction compared to other researches. FFAs were obtained, isolated, and showed their antibacterial activity against Gram-positive and Gram-negative bacteria while VCO and HVCO did not show any positive results. MIC of FFAs was determined at different concentrations. Based on that, FFAs can be used as a preservative in food products with appropriate amount in our next researches. 

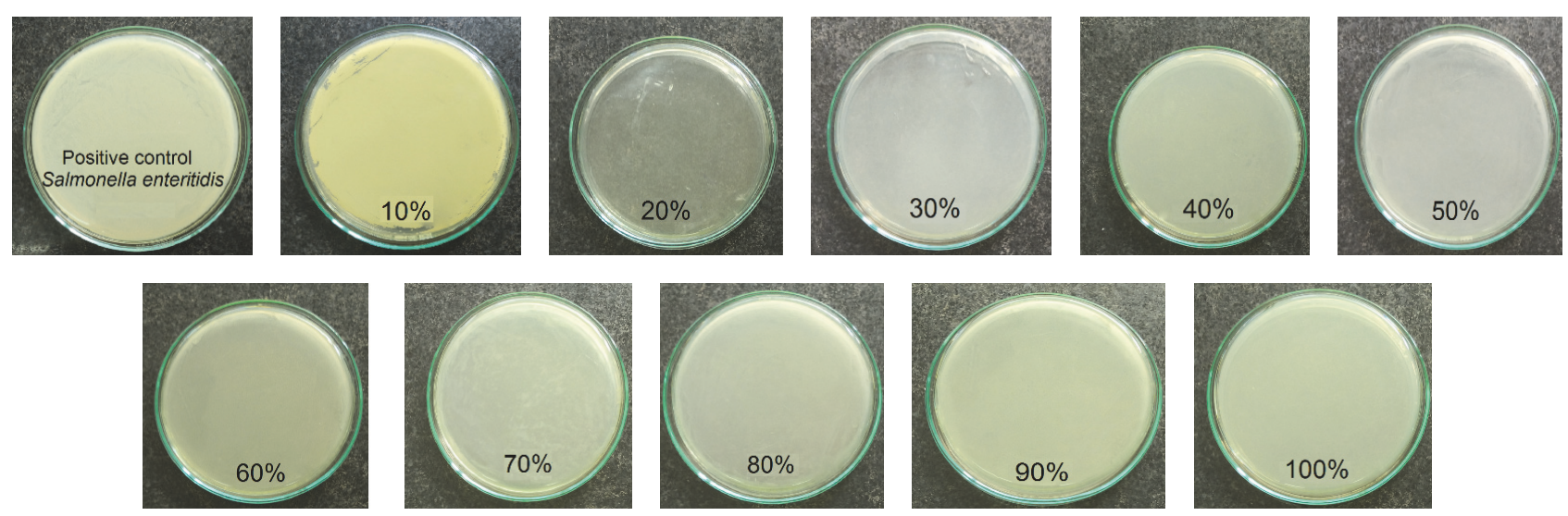

(a)
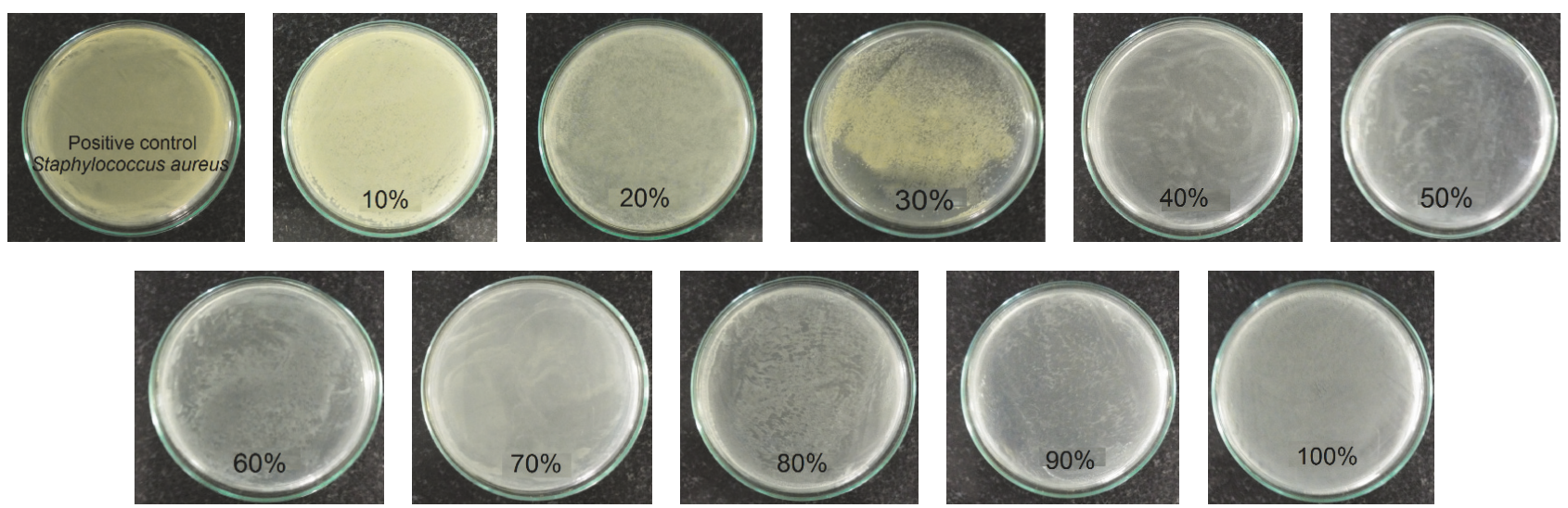

(b)

FIGURE 5: MIC of FFAs against Salmonella enteritidis (a) and Staphylococcus aureus (b).

\section{Conflicts of Interest}

The authors declare that there are no conflicts of interest regarding the publication of this paper.

\section{References}

[1] A. M. Marina, Y. B. Man, and I. Amin, "Virgin coconut oil: emerging functional food oil," Trends in Food Science \& Technology, vol. 20, no. 10, pp. 481-487, 2009.

[2] T. S. T. Mansor, M. Che, M. Shuhaimi, A. Abdul, and N. Ku, "Physicochemical properties of virgin coconut oil extracted from different processing methods," International Food Research Journal, vol. 19, no. 3, pp. 837-845, 2012.

[3] M. DebMandal and S. Mandal, "Coconut (Cocos nucifera L.: Arecaceae): in health promotion and disease prevention," Asian Pacific Journal of Tropical Medicine, vol. 4, no. 3, pp. 241-247, 2011.

[4] B. Shino, F. C. Peedikayil, S. R. Jaiprakash, G. A. Bijapur, S. Kottayi, and D. Jose, "Comparison of antimicrobial activity of chlorhexidine, coconut oil, probiotics, and ketoconazole on Candida albicans isolated in children with early childhood caries: an in vitro study," Scientifica, vol. 2016, Article ID 7061587, 5 pages, 2016.

[5] G. Parfene, V. Horincar, A. K. Tyagi, A. Malik, and G. Bahrim, "Production of medium chain saturated fatty acids with enhanced antimicrobial activity from crude coconut fat by solid state cultivation of Yarrowia lipolytica," Food Chemistry, vol. 136, no. 3-4, pp. 1345-1349, 2013.

[6] S. A. Kim and M. S. Rhee, "Highly enhanced bactericidal effects of medium chain fatty acids (caprylic, capric, and lauric acid) combined with edible plant essential oils (carvacrol, eugenol, $\beta$-resorcylic acid, trans-cinnamaldehyde, thymol, and vanillin) against Escherichia coli O157: H7," Food Control, vol. 60, pp. 447454, 2016.

[7] M. Shilling, L. Matt, E. Rubin et al., "Antimicrobial effects of virgin coconut oil and its medium-chain fatty acids on Clostridium difficile," Journal of Medicinal Food, vol. 16, no. 12, pp. 1079-1085, 2013.

[8] A. Sharma, S. P. Chaurasia, and A. K. Dalai, "Enzymatic hydrolysis of cod liver oil for the fatty acids production," Catalysis Today, vol. 207, pp. 93-100, 2013.

[9] M. C. P. Zenevicz, A. Jacques, A. F. Furigo, J. V. Oliveira, and D. de Oliveira, "Enzymatic hydrolysis of soybean and waste cooking oils under ultrasound system," Industrial Crops and Products, vol. 80, pp. 235-241, 2016.

[10] Y. Shimada, N. Fukushima, H. Fujita, Y. Honda, A. Sugihara, and Y. Tominaga, "Selective hydrolysis of borage oil with Candida rugosa lipase: Two factors affecting the reaction," Journal of the American Oil Chemists' Society, vol. 75, no. 11, pp. 1581-1586, 1998. 
[11] CLSI, Performance standards for antimicrobial disk susceptibility tests, vol. 32, 2012.

[12] Vietnamese Standard No 4884:2001, Vietnamese standardMicrobiology - General guidance for the enumeration microorganisms - Colony count technique at $30^{\circ} \mathrm{C}, 2001$.

[13] CLSI, "Methods for Dilution Antimicrobial Susceptibility Tests for Bacteria That Grow Aerobically," Approved Standard-Ninth Edition, vol. 32, no. 2, p. 287, 2012.

[14] N. A. Serri, A. H. Kamarudin, and A. Rahaman, "Preliminary studies for production of fatty acids from hydrolysis of cooking palm oil using C. rugosa lipase," Journal of Physical Science, vol. 19, no. 1, pp. 79-88, 2008.

[15] D. Goswami, J. K. Basu, and S. De, "Optimization of process variables in castor oil hydrolysis by Candida rugosa lipase with buffer as dispersion medium," Biotechnology and Bioprocess Engineering, vol. 14, no. 2, pp. 220-224, 2009.

[16] W. J. Ting, K. Y. Tung, R. Giridhar, and W. T. Wu, "Application of binary immobilized Candida rugosa lipase for hydrolysis of soybean oil," Journal of Molecular Catalysis B: Enzymatic, vol. 42, no. 1-2, pp. 32-38, 2006.

[17] L. Freitas, T. Bueno, V. H. Perez, J. C. Santos, and H. F. De Castro, "Enzymatic hydrolysis of soybean oil using lipase from different sources to yield concentrated of polyunsaturated fatty acids," World Journal of Microbiology and Biotechnology, vol. 23, no. 12, pp. 1725-1731, 2007.

[18] G.-X. Zhou, G.-Y. Chen, and B.-B. Yan, “Two-step biocatalytic process using lipase and whole cell catalysts for biodiesel production from unrefined jatropha oil," Biotechnology Letters, vol. 37, no. 10, pp. 1959-1963, 2015.

[19] M. Yiğitoğlu and Z. Temoçin, "Immobilization of Candida rugosa lipase on glutaraldehyde-activated polyester fiber and its application for hydrolysis of some vegetable oils," Journal of Molecular Catalysis B: Enzymatic, vol. 66, no. 1-2, pp. 130-135, 2010.

[20] K. Bhandari, S. P. Chaurasia, and A. K. Dalai, "Hydrolysis of tuna fish oil using Candida rugosa lipase for producing fatty acids containing DHA," International Journal of Applied and Natural Sciences, vol. 2, no. 3, pp. 1-12, 2013.

[21] D. T. Raspe, L. Cardozo Filho, and C. Da Silva, "Effect of additives and process variables on enzymatic hydrolysis of macauba kernel oil (Acrocomia aculeata)," International Journal of Chemical Engineering, vol. 2013, Article ID 438270, 8 pages, 2013.

[22] G. Bergsson, Ó. Steingrímsson, and H. Thormar, "Bactericidal effects of fatty acids and monoglycerides on Helicobacter pylori," International Journal of Antimicrobial Agents, vol. 20, no. 4, pp. 258-262, 2002. 

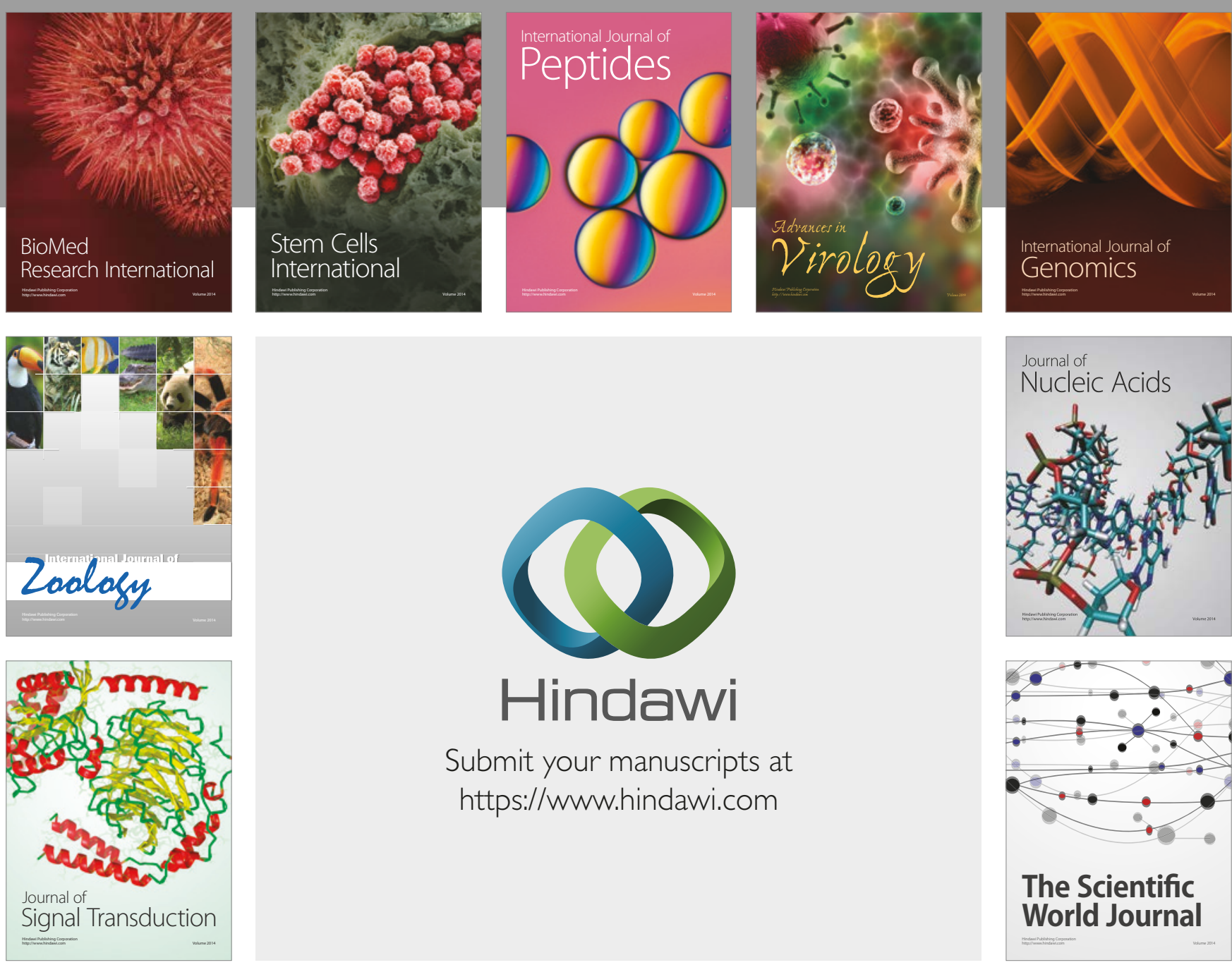

Submit your manuscripts at

https://www.hindawi.com
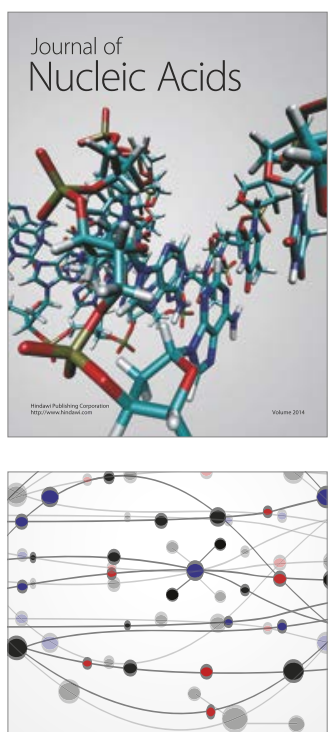

The Scientific World Journal

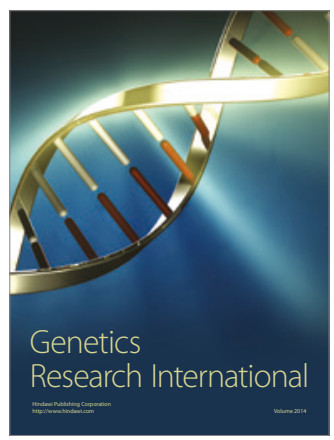

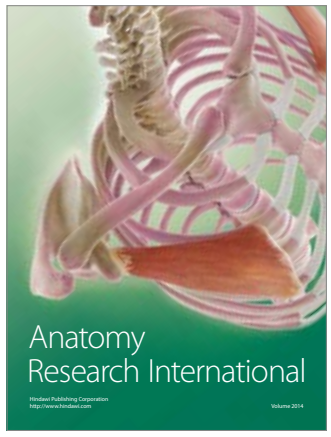

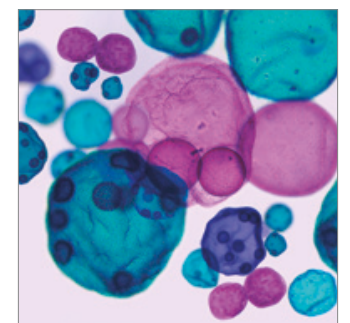

International Journal of Microbiology
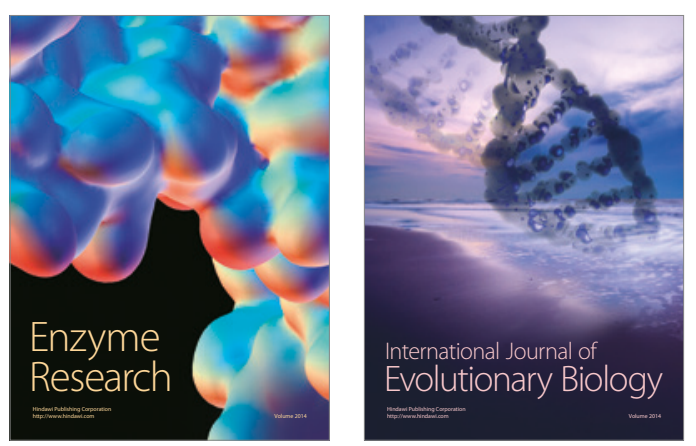
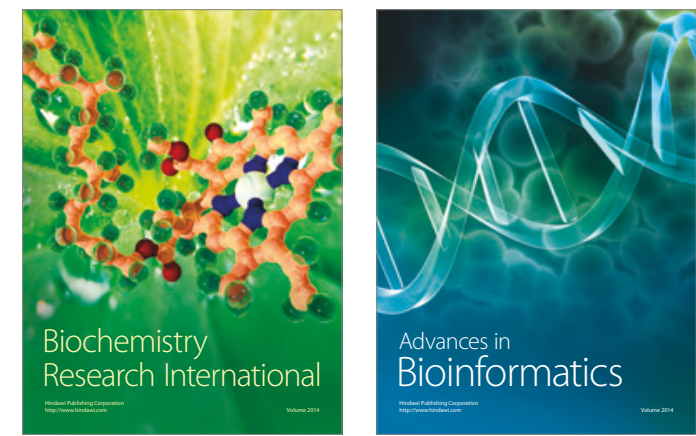

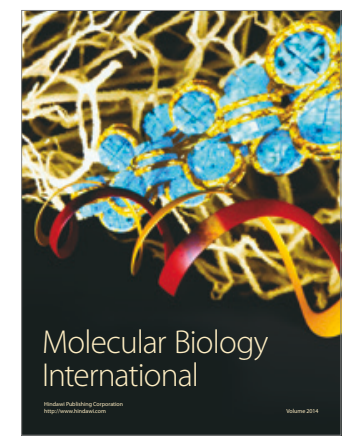

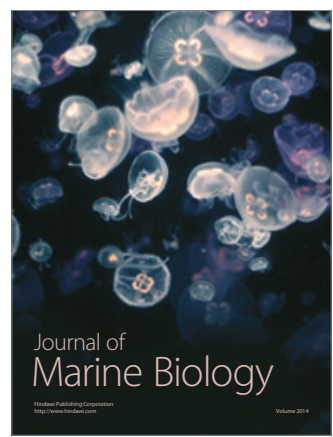

